\title{
Feelings of safety during daytime walking: associations with mental health, physical activity and cardiometabolic health in high
} vacancy, low-income neighborhoods in Detroit, Michigan

Amber L. Pearson 1,2, Kimberly A. Clevenger ${ }^{3}$, Teresa H. Horton ${ }^{4}$, Joseph C. Gardiner ${ }^{5}$, Ventra Asana ${ }^{6}$, Benjamin V. Dougherty ${ }^{1}$ and Karin A. Pfeiffer ${ }^{3 *}$ (D)

\begin{abstract}
Introduction: Individuals living in low-income neighborhoods have disproportionately high rates of obesity, Type-2 diabetes, and cardiometabolic conditions. Perceived safety in one's neighborhood may influence stress and physical activity, with cascading effects on cardiometabolic health.

Methods: In this study, we examined relationships among feelings of safety while walking during the day and mental health [perceived stress (PSS), depression score], moderate-to-vigorous physical activity (PA), Body Mass Index (BMI), and hemoglobin A1C (A1C) in low-income, high-vacancy neighborhoods in Detroit, Michigan. We recruited 69 adults who wore accelerometers for one week and completed a survey on demographics, mental health, and neighborhood perceptions. Anthropometrics were collected and A1C was measured using A1CNow test strips. We compiled spatial data on vacant buildings and lots across the city. We fitted conventional and multilevel regression models to predict each outcome, using perceived safety during daytime walking as the independent variable of interest and individual or both individual and neighborhood-level covariates (e.g., number of vacant lots). Last, we examined trends in neighborhood features according to perceived safety.

Results: In this predominantly African American sample (91\%), 47\% felt unsafe during daytime walking. Feelings of perceived safety significantly predicted PSS ( $\beta=-2.34, p=0.017)$, depression scores $(\beta=-4.22, p=0.006)$, and BMI ( $\beta=-2.87, p=0.01)$, after full adjustment. For PA, we detected a significant association for sex only. For A1C we detected significant associations with blighted lots near the home. Those feeling unsafe lived in neighborhoods with higher park area and number of blighted lots.

Conclusion: Future research is needed to assess a critical pathway through which neighborhood features, including vacant or poor-quality green spaces, may affect obesity—via stress reduction and concomitant effects on cardiometabolic health.
\end{abstract}

Keywords: Ethnic minority, Inequality, Stress, Green space, Crime

*Correspondence: kap@msu.edu

${ }^{3}$ Department of Kinesiology, Michigan State University, East Lansing, MI,

USA

Full list of author information is available at the end of the article

c) The Author(s) 2021. This article is licensed under a Creative Commons Attribution 4.0 International License, which permits use, sharing, adaptation, distribution and reproduction in any medium or format, as long as you give appropriate credit to the original author(s) and the source, provide a link to the Creative Commons licence, and indicate if changes were made. The images or other third party material in this article are included in the article's Creative Commons licence, unless indicated otherwise in a credit line to the material. If material is not included in the article's Creative Commons licence and your intended use is not permitted by statutory regulation or exceeds the permitted use, you will need to obtain permission directly from the copyright holder. To view a copy of this licence, visit http://creativeco mmons.org/licenses/by/4.0/. The Creative Commons Public Domain Dedication waiver (http://creativecommons.org/publicdomain/ zero/1.0/) applies to the data made available in this article, unless otherwise stated in a credit line to the data. 


\section{Introduction}

Individuals living in low-income neighborhoods have disproportionately high rates of obesity, Type- 2 diabetes, and cardiometabolic conditions, all of which have stressand physical activity-related etiologies [1-4]. In such neighborhoods, multiple risks operate, whereby physical activity (PA) levels are low and stress levels are high $[5,6]$, which leads to downstream inflammatory changes that alter body composition and metabolic and immune functions linked to chronic disease [7-10]. The theory of allostasis describes the reciprocal pathways by which the brain and body regulate myriad hormonal, neural, and immunological mechanisms by which exposure to chronic stress, including stressors resulting from neighborhood characteristics, increase risk of chronic disease across the life-span [11-13]. As part of the allostatic process of adapting to chronic stress, synaptic connections in the brain and epigenetic changes may occur. Ultimately, this may alter behavioral and endocrine readiness to respond to environmental triggers $[14,15]$. Thus, it is important to recognize that perceptions of neighborhood conditions contribute to stress and influence healthrelated behaviors $[16,17]$.

Neighborhoods with poor social conditions, including high deprivation levels, crime and lack of destinations or amenities have been shown to affect stress, PA behaviors and BMI of their residents [18-21]. In addition, high levels of blighted lots or structures have been shown to affect mental health, including depression [22, 23]. Green space, in particular, has been shown to both promote and hinder crime and perceptions of safety [24-26], with potential effects on PA behaviors and stress [27-29]. Likewise, greener neighborhoods consistently predict lower obesity rates across age groups and rural/urban settings [21,30-35]. Thus, evidence suggests that these neighborhood conditions play a role in physical health.

In addition, feelings of safety and fear of crime in one's neighborhood have been shown to influence mental and physical health, including depressive symptoms [36] and indices of physical wellbeing [19]. Lack of perceived safety may also lead to lower levels of outdoor PA [3740] and concomitant effects on cardiometabolic health [41]. Specifically, stress and inactivity can both lead to downstream inflammatory changes that alter body composition and metabolic and immune functions linked to chronic disease [7-10]. The primary neuroendocrine pathway conveying information about environmental stress is the hypothalamic-pituitary-adrenal axis [7, 42, 43]. This axis, in conjunction with the sympathetic and parasympathetic nervous systems [44-47], regulates many interconnected downstream pathways that alter body composition and metabolic, cardiovascular, and immune functions linked to chronic disease [7-10].
While acute stress responses may protect against threats, chronic stress and downstream inflammatory changes lead to chronic disease [42, 48, 49]. Many of these same cardiometabolic outcomes are influenced by PA $[9,10$, 50-54]. High levels of chronic disease have thus been, in part, attributed to both stress and physical inactivity [55, 56].

Cardiometabolic biomarkers including glycated hemoglobin (A1C) are useful in population-based studies of chronic disease as they reveal disease risk changes well ahead of clinical disease. Elevated $\mathrm{A} 1 \mathrm{C}$, a marker for CVD risk and Type-2 diabetes, is a marker of chronic high blood glucose levels and insulin resistance, which can result from obesity, elevated cortisol and in response to inflammation [57-60]. Just as research shows that low PA and high stress have deleterious health effects, studies underscore the twinned health benefits whereby engaging in PA not only contributes to weight management, but also lowers stress [61]. Lower stress assists with sustained weight loss [62] and improved cardio-metabolic health [63].

Feeling safe to walk in one's neighborhood during the day is of particular importance. Not only is walking a critical form of PA, but the daytime is when most businesses are open, and walking may be more commonly used as transportation among low-income populations. Likewise, differences in neighborhood lighting are inconsequential during the day. Yet, most studies related to perceptions of safety involve higher income neighborhoods and nonminority participants despite evidence that lower income groups may benefit more from improvements in neighborhood conditions.

Despite previous research on the mechanisms through which feelings of safety influence health, several research gaps remain. First, emerging research argues that neighborhood effects on health and behaviors may be more pronounced in low-income as compared to wealthier neighborhoods or among some subpopulations because individual-level factors interact with features of the risk environment to increase the vulnerability of individuals to such environments [64]. In fact, some studies have shown that improved neighborhood conditions (e.g., higher amounts of greenery) in low-income neighborhoods yield larger benefits, particularly for mental health [65], than those in more advantaged neighborhoods. Yet, most studies on feelings of safety have been conducted in middle- to high-income areas and in majority ethnicity samples. For example, studies of the effect of fear of crime or perceived safety have been conducted in US, New Zealand and Australian contexts among samples with high levels of education [36] and income [36, 41], majority white/European $[19,36,39,66]$ and employment [19]. Other studies omitted sample demographic 
information [38], including ethnicity [41]. Second, and in contrast, one study suggests that perceptions of safety are higher among African Americans, compared to other groups [39]. If consistently true, this could mean that perceptions of safety are less of a deterrent to healthy behaviors or have a smaller effect on health outcomes, compared to other groups. Therefore, exploring how feelings of safety influence health and related behaviors in low-income neighborhoods and minority populations fills a critical gap in our understanding.

Even within low-income neighborhoods, there may be micro-spatial (e.g., block-to-block) factors which influence health and related behaviors. For example, when living between two vacant homes or on a block with high vacancy, one might feel less safe about leaving home on foot. Similarly, high levels of 'signs of disorder' including broken windows, graffiti, unmaintained greenspaces, etc. may hinder feelings of safety for neighborhood walking. Understanding relationships between feelings of safety and health and the micro-spatial neighborhood conditions that support or hinder feelings of safety in such communities may offer critical insights to addressing pervasive socioeconomic inequalities in obesity, Type- 2 diabetes, and cardiometabolic health.

The objective of this study was to examine relationships between feelings of safety during daytime walking and mental health [perceived stress score (PSS), depression score], PA behaviors and cardiometabolic health [Body Mass Index (BMI), hemoglobin A1C (A1C)] in two low-income, high-vacancy neighborhoods in Detroit, MI, USA. We hypothesize that lower perceived neighborhood safety is associated with (1) lower PA; (2) poorer mental health (stress and depression); and (3) poorer cardiometabolic health (higher BMI and $\mathrm{A} 1 \mathrm{C}$ ).

\section{Methods}

\section{Sample}

Throughout America's post-industrial cities, such as Detroit, severe population decline has led to high numbers of empty lots, abandoned buildings, blighted areas and unmaintained parks (as designated by the Detroit Parks and Recreation Department). We defined blighted lots as vacant lots with inactivity, presence of dumping, or lack of maintenance. We defined blighted structures as needing demolition, being vacant, having dumping, evidence of fire, or lack of security (e.g., broken windows that could be entered). From May-August 2018, we recruited 69 participants from several blocks in Detroit (IRB Approval \#STUDY00000587) (Fig. 1). The study areas were selected due to their high levels of vacancy and poverty and their potential inclusion in a future community-level intervention for these reasons. Specifically, our sample intentionally included areas with unmaintained parks, as these are areas of potential change, through park restoration or community action (Fig. 2). This means that our sample may have higher proportions of African Americans, higher unemployment, vacancy and poverty than Detroit as a whole. We used a community-based sampling approach, whereby all eligible individuals within the study area were recruited for participation.

We mailed postcards to every home within the study area and staffed recruitment tables at prominent locations (e.g., in parks, in front of supermarkets) in each neighborhood, then approached households doorto-door for participation. Field staff were residents of Detroit who attended and successfully completed a one-week intensive training session on building rapport, participant recruitment, consent, use of tablets for data collection, finger stick tests, and anthropometrics. Staff were trained by a Kinesiology Ph.D. student and a senior biological Anthropologist, both authors on this study. We included only one English-speaking adult ( $\geq 18$ years old) without mobility issues per household. We recruited as many participants as possible with the time and limited funding.

Participants who provided written consent wore an accelerometer for 1 week and completed a survey to provide demographic data: age, sex, ethnicity, employment, length residency, marital status, home ownership, household composition, as well as perceived stress, depressive symptoms, and perceptions of the neighborhood. One week later, participants attended an appointment, where anthropometrics and $\mathrm{A} 1 \mathrm{C}$ were measured. Participants who completed perceptions of neighborhood safety and demographic survey data $(n=64)$ were included in descriptive analyses. Only participants who also had adequate accelerometer wear time (details below) were included in inferential analyses $(\mathrm{n}=58)$.

\section{Perceived stress and depression scores}

To measure stress, we collected perceived stress via a paper survey. The PSS is comprised of 10 items (e.g., feeling nervous) measured on a Likert-type scale, which has been validated extensively in different settings [67]. PSS scores are created by reverse scoring responses to the four positively stated items and then summing across all scale items, whereby higher scores indicated more stress $(\max =40)$. Using methods from previous research [68], we imputed missing items within the PSS by carrying forward the response from the previous item when fewer than four responses were missing. Items $4,5,7$ and 8 were first reverse coded (positively stated items). So, for example, when item 3 was missing, the response for item 2 was be used. When item 1 was missing, the response for item 10 was used. We used the imputed data for all 


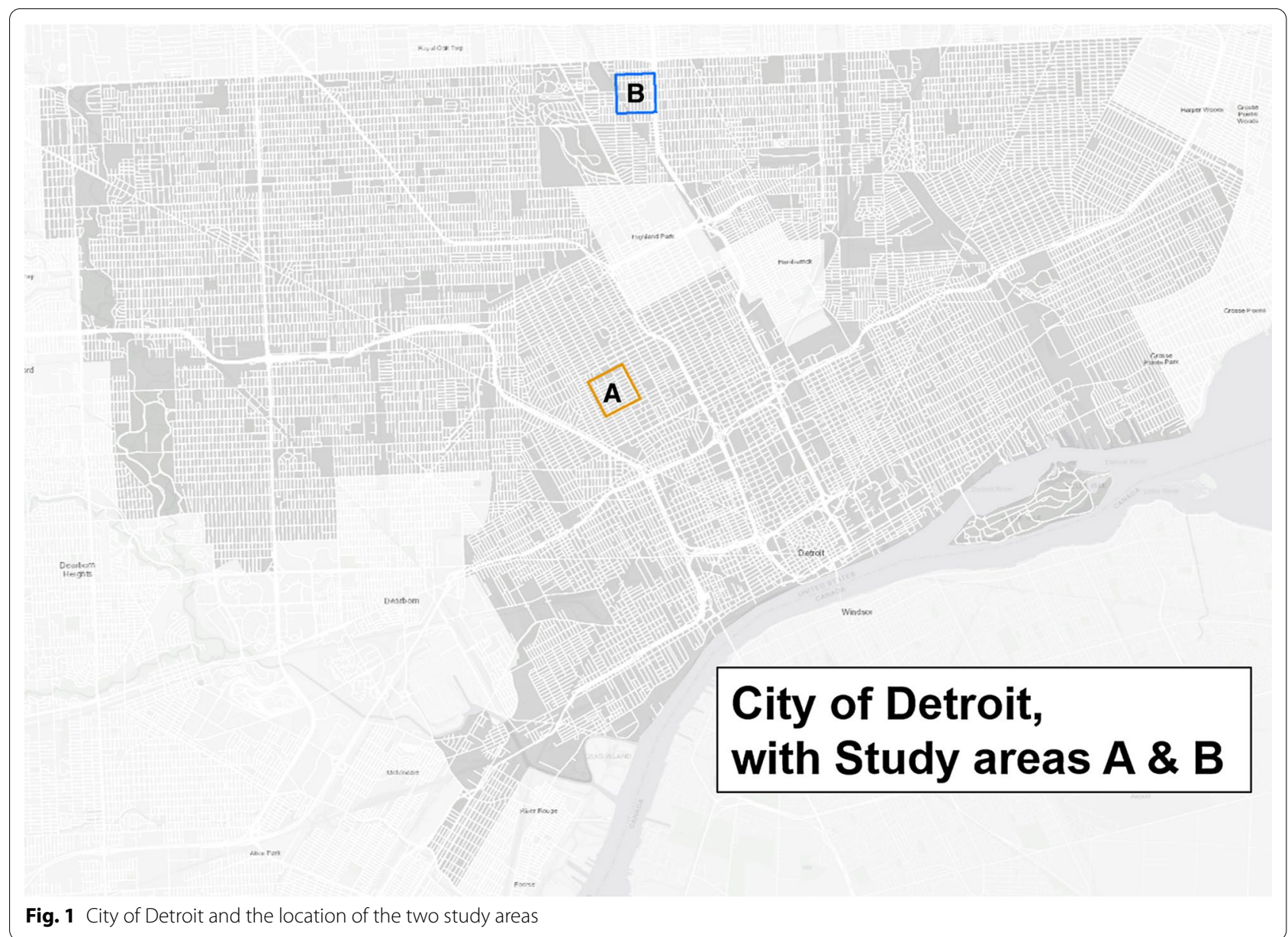

analyses, as we detected $<10 \%$ difference in coefficients on the non-imputed versus imputed data. In our sample, the Cronbach's $\alpha$ (a measure of internal consistency, often used for indices or scales) for PSS was greater than 0.7 and therefore deemed acceptable or good (0.77). The perceived stress scale's face validity and scale content were ranked high with a Kaiser-Meyer-Olkin coefficient (a measure of how well the data are suited for factor analysis) of 0.82 [69]. The scale's internal consistency reliability was good in multiple languages and convergent validity was supported by expected relationships with other mental health measures, including anxiety and depression [70]. In our sample, scores ranged from 4 to 34 .

Depressive symptoms were collected via NIH's Adult PROMIS-29 Profile v2.0 [71, 72], and t-scores were generated by comparing values to the online tool reference population, the 2000 general US census population (mean of 50, standard deviation of 10). Lower t-scores represent more favorable outcomes. PROMIS measures have been shown to significantly change in diverse clinical samples, following interventions likely to influence negative affect [73]. The PROMIS-29's internal consistency for sub-domains has been shown to be high (Cronbach's $\alpha>0.88$ ), with adequate structural validity for most domains $(\mathrm{CFI}>0.95$, RMSEA $<0.05$, both metrics are model fit indices) [74]. In our sample, the Cronbach's $\alpha$ for depression variables was excellent (0.95). In our sample, scores ranged from 41 to 79 .

\section{Physical activity levels}

Participants wore a triaxial accelerometer on an elastic belt around their waist, positioned over the right hip, during waking hours for 1 week. Due to limited funding, two accelerometer models were used (ActiGraph GT3X and wGT3X-BT), which measured acceleration at a sampling rate of $30 \mathrm{~Hz}$ to generate activity counts/60s. Published research suggests comparability between accelerometer models [75]. Non-wear time was defined as $60 \mathrm{~min}$ of continuous zeros and at least four days, of at least $480 \mathrm{~min}$ of valid wear data, were required for inclusion in subsequent analysis [76, 77]. Minutes/day of moderate-to-vigorous PA (MVPA) were determined using the Freedson et al. [78] cut-points, which is the most widely 


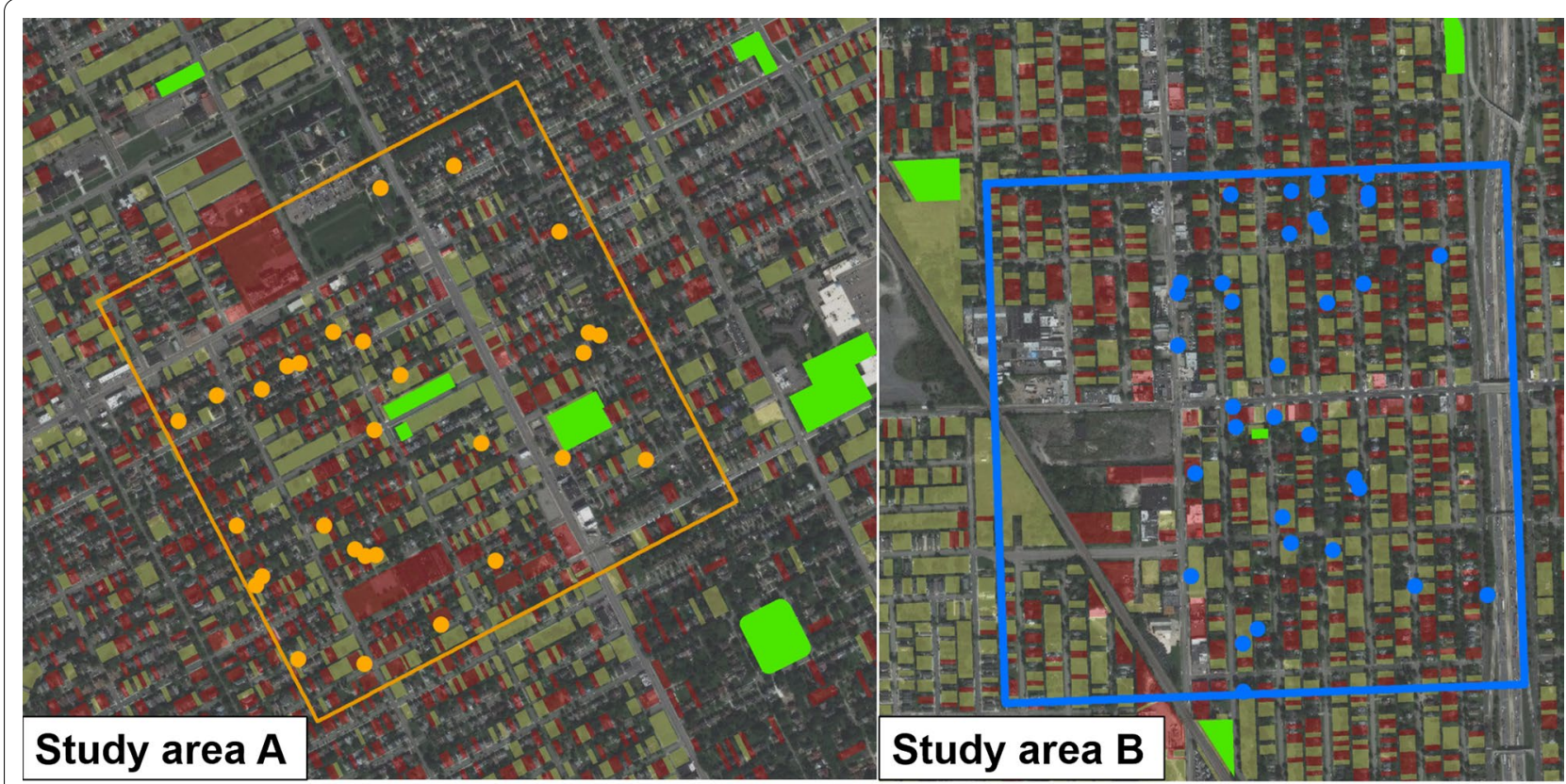

\section{$\square$ Vacant lot \\ $\square$ Blighted building \\ $\square$ Park \\ OO Jittered locations of participants}

Fig. 2 Study areas A and B, each containing high levels of vacant lots and blighted buildings and a park. Blight data republished from Data Driven Detroit under a CC BY license, with permission from Data Driven Detroit, original copyright 2013

used classification scheme for accelerometer-measured PA in adults [77].

\section{$\mathrm{A} 1 \mathrm{C}$ and $\mathrm{BMI}$}

A1C $[16,60]$, which is an indicator of blood glucose levels over the prior 3-months and is often used to test for prediabetes, was measured from blood samples collected from finger-tip sticks using portable analyzers and test strips (A1CNow ${ }^{+}$, PTS Diagnostics), previously shown to be valid compared to lab-based analysis [79]. Stature was measured using a portable stadiometer (SECA Corp) and mass was measured using a digital scale (Tanita). Two measurements were taken and averaged. BMI values were calculated as $\mathrm{kg} / \mathrm{m}^{2}$.

\section{Perceptions of neighborhood daytime safety}

Perceived neighborhood safety was assessed as whether or not a participant feels safe walking during the day [80]. We asked: "The crime rate in my neighborhood makes it unsafe to go on walks during the day." Responses were recorded on a Likert-type scale for level of agreement. These were aggregated to three levels, where $1=$ "Strongly Agree" or "Agree a Little"; $2=$ "Neither Agree nor Disagree"; and 3= "Strongly Disagree" or "Disagree a Little". The purpose of walking was not specified in the question (i.e., for leisure or for transportation). Questions about the perceptions of the neighborhood [80-84] such as feelings of safety [19], have been shown to have moderate to high agreement or correlation (rho range $=0.42-0.91)[81]$.

\section{Area-level characteristics}

Consistent with theoretical area-level drivers of both mental health and cardiometabolic health, we also compiled additional area-level characteristics for correlation analyses including deprivation, crime, blighted lots or structures, and green space. In this study, we included a crime index (both property and violent crime). Each participant was assigned a value based on their home location's census block. This index is part of the Neighborhood Change Index created by Data Driven Detroit $\left(D^{3}\right)$ in October 2018, for the 'Turning the Corner' project using 2010 census blocks [85]. The following Detroit datasets were used by $\mathrm{D}^{3}$ : City of Detroit Building, Safety Engineering and Environmental Department, Department of Administrative Hearings, Data Driven Detroit's Rental Property Analysis, Fire Department, Police Department, Water and Sewerage Department, DTE Energy, and Property Praxis [85]. D ${ }^{3}$ excluded: (1) blocks with five or fewer residential structures according 
to a 2014 in-person audit; (2) blocks where fewer than $25 \%$ of parcels had a residential structure; and (3) blocks where the median home value exceeds $\$ 150,000$ using the American Community Survey, 2011-2015. With all remaining blocks, $\mathrm{D}^{3}$ generated $\mathrm{z}$-scores for each variable at the block level. After factor analysis, only those with heavy loadings $(>0.45)$ were kept. Z-scores of relevant indicators were averaged to create index variables. Index values range from 1 (low) to 5 (high).

We also included the number of blighted lots and blighted structures within a $100 \mathrm{~m}$ Euclidean (as the crow flies) buffer around each participant's home, based on 2014 data from in-person audits (Motor City Mapping Project [86]). We also calculated the area of each buffer covered by a park, using data from the Detroit Parks and Recreation Department. Last, we assigned each participant the area deprivation rank score based on their census block group, calculated from 2013 census data and compiled by the University of Wisconsin [87]. All spatial techniques were conducted using ArcMap v10.6 (ESRI, Redlands, CA).

\section{Statistical analyses}

For continuous and categorical variables, we calculated averages or percentage values for the whole sample and stratified by level of perceived safety during daytime walking. We also tested for significant differences in demographic and health measures by level of feelings of safety. For binary variables, we calculated p-values using chi-square exact test; for continuous variables, we calculated $\mathrm{p}$-values using Wilcoxon test.

Next, for each outcome separately, we fitted two linear models. All outcome variables (perceived stress scores, depression t-scores, BMI, A1C and square root of MVPA) were all treated as continuous variables. The square root transformation was applied to MVPA to mitigate skewness. The independent variable of interest, feelings of safety during daytime walking, was treated as an ordinal variable. The first model included individual-level covariates (age was treated as a continuous variable; sex and employment were treated as binary variables). The second model included both individual and area-level covariates (blighted lots was treated as a continuous variable; crime index was treated as an ordinal variable). A random effect for block level is included in all models to capture possible correlation between subjects within block. ICC (intra-class correlation) could be viewed as a correlation in outcomes between subjects in the same block. None of ICCs of the null models for the five outcomes were statistically significant, except for A1C $(\mathrm{ICC}=0.657)$. Last, we examined neighborhood features according to level of perceived safety during daytime walking and used a Spearman's correlation coefficient (rho) to evaluate relationships between feelings of safety and neighborhood characteristics due the ordinal nature of feelings of safety. All statistical analyses were conducted using Stata v16 (Statacorp, College Station, TX) and SAS Software ver 9.4 (SAS Institute Inc, Cary, NC).

\section{Results}

On average, participants who felt unsafe walking during the day were slightly older, had fewer children, and lived in their neighborhood for less time (Table 1). Generally, African-Americans (91\% of our sample), employed participants and single people more often reported feeling unsafe walking during the day. In contrast, among those that felt safe walking during the day, $63 \%$ were female, $80 \%$ were African American, 47\% were employed, 20\% were married or partnered, and $43 \%$ owned their home. We also observed a clear gradient between feelings of safety and perceived stress scores and lower depressive scores among those feeling safe walking. We observed higher levels of PA among those feeling unsafe, but this group also had higher BMI and A1C. We also observed a trend toward higher crime, more blighted lots and buildings, and higher park area among those we felt unsafe walking during the day. The only significant differences across levels of feelings of safety were found for African Americans $(\mathrm{p}=0.036)$ and depressive symptoms $(\mathrm{p}=0.006)$.

Compared to the blockgroups from which our sample was taken, our sample had slightly lower percentage females, home ownership and number of children, slightly higher percentage African Americans, higher employment and married percentages (although census data do not include partnered adults). Compared to Detroit as a whole, our sample had slightly lower percentage females, home ownership and number of children, and higher percentage African Americans.

Feelings of safety during daytime walking was significantly negatively associated with both PSS and depressive symptoms, regardless of level of confounder control (Table 2, Models A-D). When feelings of safety were higher, PSS and depressive symptoms were significantly lower. As seen in Fig. 1, the study areas have high numbers of blighted, vacant lots and there is high variation from one block to another. Despite this variation, the number of blighted lots or crime index values did not significantly influence mental health measures, independent of feelings of safety while walking (Table 2, Models B and D). In fact, when neighborhood confounders were added to individual-level confounders, the absolute value of the coefficient $(\beta)$ increased for PSS. No other covariates showed significant, independent effects.

For PA, the only significant predictor was sex (Table 2), whereby we would expect around 19.3 more minutes of 
Table 1 Sample characteristics, stratified by level of perceived safety during daytime walking and for the total sample

\begin{tabular}{|c|c|c|c|c|c|c|}
\hline & $\begin{array}{l}\text { Feel unsafe } \\
\text { walking }\end{array}$ & Neutral & $\begin{array}{l}\text { Feel safe } \\
\text { walking }\end{array}$ & $\begin{array}{l}\text { Total in our } \\
\text { sample }\end{array}$ & $\begin{array}{l}\text { Blockgroup data } \\
\text { for our study } \\
\text { area }^{\text {a }}\end{array}$ & $\begin{array}{l}\text { Blockgroup } \\
\text { data for } \\
\text { Detroit }^{\mathrm{a}}\end{array}$ \\
\hline N & 24 & 10 & 30 & 64 & 6456 & $1,339,576$ \\
\hline Female, \% & 45.8 & 90 & 63.3 & 60.9 & 69.9 & 68.5 \\
\hline African-American, \% & 100 & 100 & 80 & 90.6 & 86.7 & 47.5 \\
\hline Employed, \% & 60.9 & 44.4 & 46.7 & 51.6 & 38.5 & 53 \\
\hline Married or partnered, \% & 12.5 & 11.1 & 20 & 15.9 & $5.1^{\mathrm{b}}$ & $13.2^{b}$ \\
\hline Own home, \% & 34.8 & 11.1 & 42.9 & 35 & 56.8 & 62.1 \\
\hline Number children, mean (sd) & $1.0(1.4)$ & $1.9(3.0)$ & $0.5(0.9)$ & $0.9(1.6)$ & $0.3(0.2)$ & $0.3(0.2)$ \\
\hline Age, mean years $(\mathrm{sd})$ & $44.7(13.9)$ & $43.4(18.0)$ & $42.9(15.9)$ & $43.7(15.3)$ & & \\
\hline Length residency, mean years (sd) & $4.1(4.4)$ & $5.0(2.8)$ & $8.6(11.3)$ & $6.3(8.4)$ & & \\
\hline Perceived stress score, mean (sd) & $19.3(6.9)$ & $18.8(5.2)$ & $15.2(6.1)$ & $17.3(6.5)$ & & \\
\hline Depressive symptoms, mean (sd) & $56.7(11.6)$ & $57.9(9.0)$ & $48.3(9.0)$ & $52.9(10.8)$ & & \\
\hline MVPA, min/day mean (sd) & $28.1(22.5)$ & $18.2(11.4)$ & $19.5(22.7)$ & $22.8(21.4)$ & & \\
\hline $\mathrm{BMI}, \mathrm{kg} / \mathrm{m}^{2}$ mean $(\mathrm{sd})$ & $32.8(8.5)$ & $30.4(6.1)$ & $29.0(6.8)$ & $30.7(7.5)$ & & \\
\hline$A 1 C, \%$ mean $(s d)$ & $5.8(1.5)$ & $5.4(1.4)$ & $5.4(0.7)$ & $5.5(1.2)$ & & \\
\hline Crime index ${ }^{c}$, mean (sd) & $3.3(1.3)$ & $3.2(1.5)$ & $3.1(1.5)$ & $3.2(1.4)$ & & \\
\hline Blighted lots, mean (sd) & $22.4(10.8)$ & $18.5(11.2)$ & $15.6(9.7)$ & $18.6(10.7)$ & & \\
\hline Blighted buildings, mean (sd) & $18.1(7.3)$ & $17.8(10.1)$ & $17.7(8.3)$ & $17.9(8.1)$ & & \\
\hline Area of park in km, mean (sd) & $0.7(1.6)$ & $0.2(0.6)$ & $0.3(1.1)$ & $0.4(1.3)$ & & \\
\hline
\end{tabular}

MVPA moderate-to-vigorous intensity physical activity, BMI body mass index, $A 1 C$ glycated hemoglobin

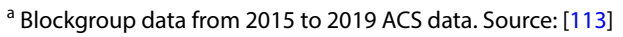

${ }^{\mathrm{b}}$ Census data do not include partnered adults

${ }^{c}$ Quintiles from high (5) to low (1)

moderate-to-vigorous PA per day for males compared to females, after accounting for all covariates (Model F). For BMI, we observed significant, negative associations with perceived safety during daytime walking (Table 2, Models $\mathrm{G}$ and $\mathrm{H})$. In the fully adjusted model, we would expect 2.9 lower BMI for every one-point increase in perceived safety. Female sex was also significantly associated with higher BMI. For A1C, we observed an unexpected negative association with the number of blighted lots within $100 \mathrm{~m}$ (Table 2, Model J).

In terms of area-level factors of perceived safety during daytime walking, most correlations were weak (Table 3). We observed the largest correlations for blighted lots, area deprivation and park area, respectively. The average number of blighted lots near those feeling unsafe was 22.4, compared to 15.6 for those feeling safe. Participants' feelings of safety and the number of blighted lots near their home was significantly correlated $(\mathrm{rho}=-0.288$, $\mathrm{p}=0.022$ ). Participants' feelings of safety was weakly, negatively correlated with the level of area deprivation (rho $=-0.148, \mathrm{p}=0.246)$, although not statistically significant. Also, participants' feelings of safety was negatively, weakly correlated with the extent of park area near their home ( $r h o=-0.135, \mathrm{p}=0.295)$, although again not statistically significant. Mean crime index scores were slightly lower in areas where residents reported feeling safe, but the correlation was non-significant.

\section{Discussion and conclusion}

Overall, in this predominantly African American sample, $47 \%$ felt unsafe during daytime walking. We did not confirm our hypothesis that lower perceived neighborhood safety is associated with lower PA, as the only significant variable was sex. Our second hypothesis that lower perceived neighborhood safety would be associated with poorer mental health (stress and depression) was confirmed after full adjustment of covariates. We partially confirmed our third hypothesis that lower perceived neighborhood safety would be associated with poorer cardiometabolic health; only higher BMI, but not A1C, was related (after full adjustment for covariates). Additionally, those feeling unsafe lived in neighborhoods with higher park area and number of blighted lots. Thus, findings were mixed compared to the expected nature of the relationships examined.

It is important to consider that nearly half of the sample did not report feeling safe walking in their neighborhood during the daytime. Because walking is an important form of exercise [88] and walking near home is accessible to those without a vehicle or is needed to 
take advantage of public transportation, any obstacles to this form of exercise are highly important for cardiometabolic health in low-income populations. Our study points to one important obstacle to engaging in walking in one's neighborhood: feelings of safety. Here, we discuss our study findings, drawing comparisons to other studies in minority ethnicity, low-income samples when possible. Still, direct comparisons with such studies or studies among high-income and/or majority ethnicity samples are constrained by differences in measures of perceptions of safety, objective versus self-reported measures, and differences in health outcome measures.

\section{Perceived safety and mental health}

We found that lower feelings of safety were associated with higher stress, depression, and BMI. In contrast, feelings of safety were not associated with PA levels or A1C. These findings suggest that perceptions of safety in one's neighborhood may have a significant influence on mental health and obesity, even after accounting for recorded crime. Other research from New Zealand has shown that perceptions of safety can be quite spatially focal, whereby fear of crime was associated with recorded crime in one's own neighborhood, but not in surrounding neighborhoods [89] and that the relationship between recorded crime and fear is moderated by neighborhood social context [90]. This work also found that perceptions of lower safety were associated with poorer mental and physical outcomes, yet recorded crime had little or no independent effect on health $[19,91]$, echoing our findings. Our findings are also in line with a growing body of evidence that shows that lack of perceived safety can negatively affect anxiety [92, 93], psychological distress [94, 95], mental wellbeing [19] and depressive symptoms [36]. Interestingly, one study found that the association between higher perceived safety was associated with better mental health outcomes was mediated by PA [96]. A caveat to this study is that perceived neighborhood safety was determined by 30 university volunteers using imagery of neighborhoods, rather than the participants for which outcomes were measured.

No other demographic covariates were independently associated with mental health after accounting for perceived safety and neighborhood conditions. This is

Table 2 Regression modelling results, for Perceived Stress Scores (Models A \& B), depressive symptoms (Models C \& D), physical activity (Models E \& F), body mass index (Models G \& H), and glycated hemoglobin A1C (Models I \& J)

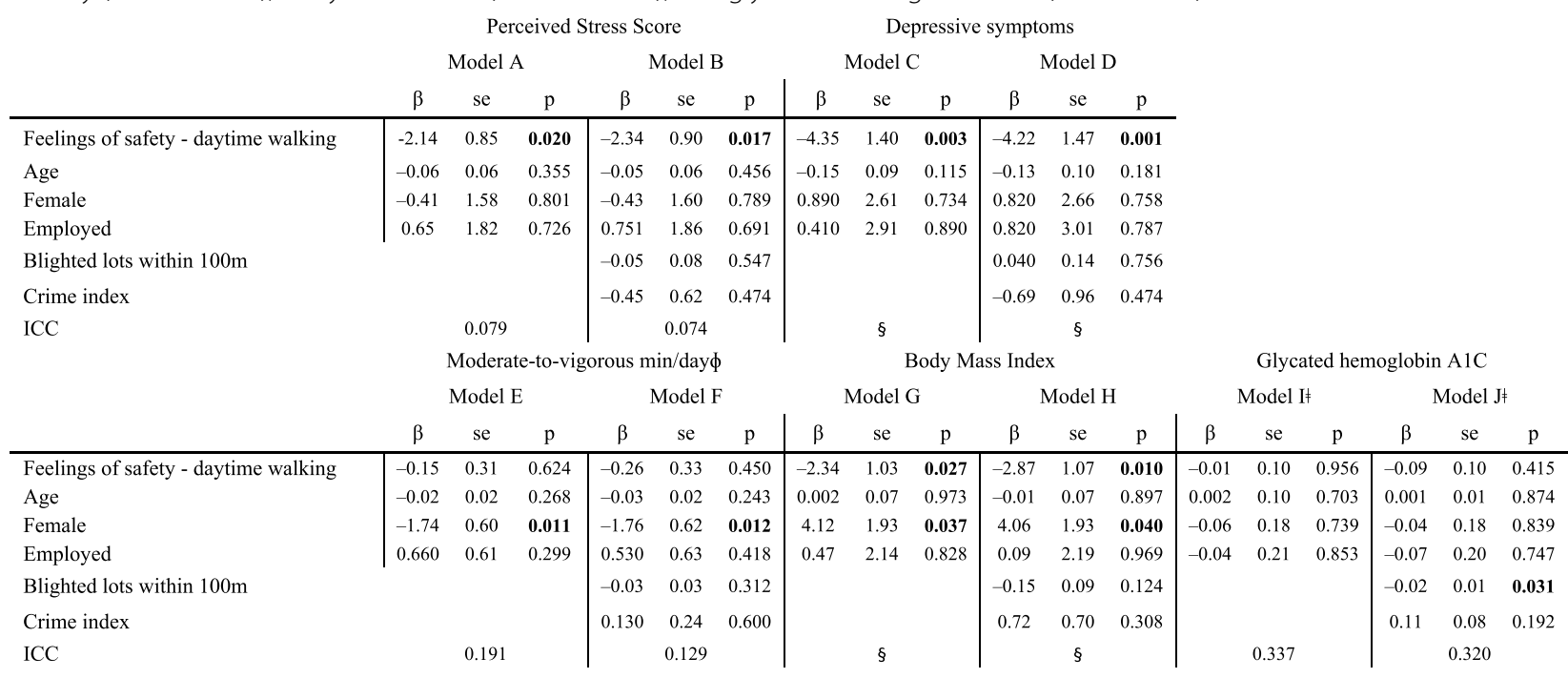

MVPA: moderate-to-vigorous intensity

physical activity; BMI: body mass index; A1C: Glycated hemoglobin

$\S$ no significant random effects

$\phi$ square root $u$ sed

₹ major outliers $(n=2)$ omitted

Bolded values are significant at $p<0.05$

level

MVPA moderate-to-vigorous intensity physical activity, $B M I$ body mass index, $A 1 C$ glycated hemoglobin

Bold italic values are significant at $\mathrm{p}<0.05$ level

${ }^{a}$ No significant random effects

b Square root used

${ }^{c}$ Major outliers $(n=2)$ omitted 
Table 3 Trends in neighborhood characteristics according to participants' perceived safety during daytime walking, including ratios and Spearman's correlations

\begin{tabular}{lcccccc}
\hline & $\begin{array}{l}\text { Feel unsafe } \\
\text { walking [1] }\end{array}$ & Neutral [2] & $\begin{array}{l}\text { Feel safe walking } \\
{[3]}\end{array}$ & Total & Spearman's rho & $\begin{array}{l}\text { Spearman's } \\
\text { p-value }\end{array}$ \\
\hline Area deprivation, mean & 9.6 & 9.5 & 9.4 & 9.5 & -0.148 & 0.246 \\
Blighted lots, mean & 22.4 & 18.5 & 15.6 & 18.6 & $-\mathbf{0 . 2 8 8}$ & $\mathbf{0 . 0 2 2}$ \\
Blighted structures, mean & 18.1 & 17.8 & 17.7 & 17.9 & -0.042 & 0.746 \\
Crime index ${ }^{\text {a }}$, mean & 3.3 & 3.2 & 3.1 & 3.2 & -0.050 & 0.700 \\
Park area in m $^{2}$, mean & 696.6 & 198.8 & 265.9 & 421.8 & -0.135 & 0.295 \\
\hline
\end{tabular}

Bolded font $\mathrm{p} \leq 0.05$

${ }^{\text {a }}$ Crime index: $5=$ more crimes, $1=$ fewer crimes

unexpected given the breadth of research showing that, in studies of perceptions of safety, mental health tend to vary by sex, age, marital status and other demographic characteristics (e.g., [19]). Our findings highlight a need for a more nuanced understanding of how perceptions of safety arise in some groups but not in others, potentially including past experiences or victimization, or social position.

\section{Perceived safety, physical activity and cardiometabolic outcomes}

Somewhat surprisingly, we found that feelings of safety were associated with BMI, but not PA levels, in contrast to some existing work [66]. A meta-analysis of the relationship between perceived safety and PA concluded that those reporting feeling safe had a $27 \%$ greater odds of having higher levels of $\mathrm{PA}(\mathrm{OR}=1.27,95 \% \mathrm{CI}=1.08$, 1.49), although effects were heterogeneous [97]. One possible explanation for our incongruent finding is that the neighborhood-obesity relationship is influenced not only by PA, but through the stress pathway [7-10]. Other studies of neighborhood conditions have also found associations with BMI but not PA. For example, many studies on neighborhood green space and health have detected significant associations with lower BMI but no association with PA [21, 30-35, 98]. Another study among socioeconomically and racially/ethnically diverse adolescents in Minneapolis found that BMI, but not PA, was positively associated with perceived crime [99]. BMI was also positively associated with lack of perceived safety in a majority Latino sample in Los Angeles [100]. In a recent study in a predominantly African American (93\%) sample, the opposite was found [101]. Specifically, perceived improvements in neighborhood safety over a 3-year period were associated with significantly higher BMI, particularly among females, but not after adjustment for baseline BMI. A second possible reason for our findings is that participants in our sample did not have adequate variation in PA levels. Overall, our sample was rather sedentary, with an average of only 23 min of MVPA per day, compared to a USA average of approximately $35 \mathrm{~min} /$ day for males and $20 \mathrm{~min} /$ day for females [88].

Unexpectedly, we also found a negative association between $\mathrm{A} 1 \mathrm{C}$ and number of blighted lots. Echoing our unexpected findings, another study comprised primarily of African Americans found a positive association between $\mathrm{A} 1 \mathrm{C}$ and perceived improvements in neighborhood safety among females only [101]. However, this relationship attenuated to non-significance after adjustment for baseline BMI. Still, these findings are surprising because qualitative research from Detroit has shown that landscape maintenance is a visible sign of care which contributes to changes in physical and social environments linked to health [102]. In that study, signs of care (e.g., mowing vacant lots) strengthened social relationships among neighbors, lowered stress and offered a coping strategy to handle stress effects. Another study had similar results in a majority African American sample, finding that percent vacancy was positively associated with fear of walking [37]. One possible explanation for our finding is that areas where demolitions are high may be areas where there is more activism to get abandoned buildings removed, thus higher numbers of vacant lots. Since we also observed higher numbers of blighted lots in areas where participants felt more unsafe, there are likely unmeasured confounders affecting our evaluation of the relationship between $\mathrm{A} 1 \mathrm{C}$ and feelings of safety.

\section{Practical implications}

Understanding the area-level conditions of those feeling unsafe may provide some insights as to potential points of intervention for improving perceived safety and associated outcomes, like perceived stress, depressive symptoms, and BMI. Those feeling unsafe lived in areas with a higher average park area and number of blighted lots. Perhaps more importantly, given our findings, unmaintained green spaces in low-income, high vacancy areas may confer negative effects. While maintained green 
spaces have been shown to promote PA and lower stress [29, 103-105], unmaintained spaces (both as parks and as vacant lots) may not yield benefits. In the worst instances, these areas become locations for drug dealing and crime in the U.S. [106]. It is important to note that in other countries unmaintained spaces may be viewed and utilized differently than those in the U.S. On the positive side, experimental studies have shown that improving poorly maintained green spaces and/or 'greening' vacant lots leads to physical health benefits, lower stress, lower neighborhood violence, and increased perceived safety $[26,107,108]$.

So, while our study showed that parks and blighted lots were more common in areas with lower perceived safety, improvements in these neighborhood features offer the promise of improved perceived safety and also health conditions. Still, beyond identifying neighborhood features that are obstacles to healthy living, future research could usefully, in countries and areas that warrant it, utilize a structural violence framework to assessing PA behaviors and cardiometabolic health, given the high levels of stress experienced in such low-income neighborhoods. Such research could examine how historical processes such as redlining, housing exclusion policies and employment opportunities create inequitable environments that influence individuals. Specifically related to fear and lack of safety, research has shown that fear, created by structural forces, is a driving factor undermining diabetes and healthcare behaviors among Hispanic communities [109]. Perhaps a similar framework can be used in future research to understand historical structural and cultural factors which produce or exacerbate fear in one's neighborhood, as this relates explicitly to PA behaviors.

\section{Study limitations}

This study has limitations to consider. The blight data were collected in 2014 and conditions may have changed. We measured total PA, rather than PA that occurred within a certain distance of their home location. It is possible that PA may have occurred in other settings: potentially less disadvantaged areas. This may, in part, explain the lack of a detected association between PA and feelings of safety. Future research could restrict analysis to only PA occurring within a certain distance from the home. Mental health measures were self-reported and it is unclear how these measures might compare to objective measures of stress (e.g., salivary cortisol). The sample size was limited in this study. For this reason, we were unable to explore the potential for the relationship between perceptions of safety and BMI to be mediated by PA. Future research with a larger sample may contribute to our knowledge with such analyses.
Another limitation of this study is the lack of data collection on diet, due to the additional burden on participants, which is also likely important for assessing drivers of BMI. We also did not measure differential access to healthy food options in the built environment. Indeed, PA alone may not be sufficient to offset the effects of poor diet [110]. Given the inconsistency in findings in the literature between neighborhood conditions and A1C [111, 112 ] and in the measurement of neighborhood safety, our non-significant but positive findings warrant further exploration in future research.

\section{Future research}

Future research is also needed to assess a critical pathway through which area-level conditions, particularly unmaintained parks and blighted vacant lots, affect obesity via stress reduction and concomitant effects on cardiometabolic health. It is unclear whether stress reduction alone leads to improved cardiometabolic health (including lower BMI) or whether PA is the precursor for stress reduction and the cascading health benefits. Correlational designs do not answer this question, as it is entirely possible that people with lower BMI or better cardiometabolic health choose to live in particular settings. Qualitative study designs may help shed light on some of the surprising findings or help untangle the ways in which perceptions of safety, personal characteristics and neighborhood conditions interact to influence health and related behaviors. Additionally, qualitative studies can shed light on how individuals from countries outside of the U.S. view neighborhood safety and characteristics compared to individuals in the U.S. Experimental or quasi-experimental designs are needed to untangle these potential neighborhood effects on behavior, weight status and downstream cardiometabolic health, particularly in low-income neighborhoods. Importantly, inexpensive park and vacant lot interventions are needed to assess causality. In low-income neighborhoods, like those studied in Detroit, such interventions are more feasible than typical park projects that install costly equipment and trail systems.

\section{Conclusions}

While it may be a challenge to eliminate chronic disease and stress, particularly in disadvantaged settings, it is the hope that promotion of PA and stress reduction may also help in the management of existing chronic diseases or stress reduction. Community-level interventions, such as neighborhood improvements that bolster safety perceptions, may offer one avenue for equitable promotion of stress reduction, and lower BMI and depression in disadvantaged neighborhoods, as our findings suggest. Still, future research is needed to assess a critical pathway 
through which neighborhood features, including vacant or poor-quality green spaces, may affect obesity-via stress reduction and concomitant effects on cardiometabolic health.

\section{Acknowledgements}

The authors wish to thank the study participants and staff, without whom this study would not be possible. We thank Nicole Conner for her leadership on the study team. We thank Grace Episcopal Church and Lincoln Library for the use of their facilities and their support of this study.

\section{Authors' contributions}

AP conceived of the study. AP led data collection, assisted by KAP, TH, BD VA and KC. AP and JG ran statistical analyses. AP drafted the manuscript. All authors edited the manuscript. All authors read and approved the final manuscript.

\section{Funding}

This study was funded by Michigan State University's Clinical and Translational Research Initiative.

\section{Availability of data and materials}

The datasets during and/or analysed during the current study available from the corresponding author on reasonable request.

\section{Declarations}

\section{Ethics approval and consent to participate}

This study was approved by MSU's IRB (Approval \#STUDY00000587). Participants provided written consent to participate.

\section{Consent for publication}

Not applicable.

\section{Competing interests}

The authors declare that they have no competing interests.

\section{Author details}

'Department of Geography, Environment \& Spatial Sciences, Michigan State University, East Lansing, MI, USA. ${ }^{2}$ Department of Public Health, University of Otago, Wellington, New Zealand. ${ }^{3}$ Department of Kinesiology, Michigan State University, East Lansing, MI, USA. ${ }^{4}$ Department of Anthropology, Northwestern University, Evanston, IL, USA. ${ }^{5}$ Department of Epidemiology and Biostatistics, Michigan State University, East Lansing, MI, USA. Independent Scholar, Detroit, MI, USA.

\section{Received: 10 December 2020 Accepted: 13 April 2021} Published online: 03 May 2021

\section{References}

1. Scott KA, Melhorn SJ, Sakai RR. Effects of chronic social stress on obesity. Curr Obes Rep. 2012;1(1):16-25.

2. Beyer KMM, Szabo A, Hoormann K, Stolley M. Time spent outdoors, activity levels, and chronic disease among American adults. J Behav Med. 2018;41(4):494-503.

3. Kumanyika SK. A framework for increasing equity impact in obesity prevention. Am J Public Health. 2019;109(10):1350-7.

4. Sallis JF, Floyd MF, Rodríguez DA, Saelens BE. Role of built environments in physical activity, obesity, and cardiovascular disease. Circulation. 2012;125(5):729-37.

5. CDC. Michigan: state nutrition, physical activity and obesity profile. Atlanta: Centers for Disease Control and Prevention; 2016.

6. Weissman J, Pratt LA, Miller EA, Parker JD. Serious psychological distress among adults: United States, 2009-2013. Washington, DC: US Department of Health and Human Services, National Center for Health Statistics; 2015. Contract No. 203.
7. Eskandari F, Sternberg EM. Neural-immune interactions in health and disease. Ann NY Acad Sci. 2002;966:20-7.

8. Juster RP, McEwen BS, Lupien SJ. Allostatic load biomarkers of chronic stress and impact on health and cognition. Neurosci Biobehav Rev. 2010;35(1):2-16.

9. Eyre HA, Papps E, Baune BT. Treating depression and depression-like behavior with physical activity: an immune perspective. Front Psych. 2013;4:3.

10. Wolff-Hughes DL, Fitzhugh EC, Bassett DR, Churilla JR. Total activity counts and bouted minutes of moderate-to-vigorous physical activity: relationships with cardiometabolic biomarkers using 2003-2006 NHANES. J Phys Act Health. 2015;12(5):694-700.

11. McEwen BS. Allostasis and the epigenetics of brain and body health over the life course: the brain on stress. JAMA Psychiatry. 2017;74(6):551-2.

12. Tan M, Mamun A, Kitzman H, Mandapati SR, Dodgen L. Neighborhood disadvantage and allostatic load in African American women at risk for obesity-related diseases. Prev Chronic Dis. 2017;14:E119.

13. Prior L, Manley D, Jones K. Stressed out? An investigation of whether allostatic load mediates associations between neighbourhood deprivation and health. Health Place. 2018;52:25-33.

14. Leuner B, Shors TJ. Stress, anxiety, and dendritic spines: what are the connections? Neuroscience. 2013;251:108-19.

15. Giurgescu C, Nowak AL, Gillespie S, Nolan TS, Anderson CM, Ford JL, et al. Neighborhood environment and DNA methylation: implications for cardiovascular disease risk. J Urban Health. 2019;96(Suppl 1):23-34

16. Ludwig J, Sanbonmatsu L, Gennetian L, Adam E, Duncan GJ, Katz LF et al. Neighborhoods, obesity, and diabetes - a randomized social experiment. N Engl J Med. 2011;365(16):1509-19.

17. Boehmer TK, Hoehner CM, Deshpande AD, Brennan Ramirez LK, Brownson RC. Perceived and observed neighborhood indicators of obesity among urban adults. Int J Obes. 2007;31(6):968-77.

18. Jenkin GL, Pearson AL, Bentham G, Day P, Kingham S. Neighbourhood influences on children's weight-related behaviours and BMI. AIMS Public Health. 2015:2(3):501-15.

19. Pearson AL, Breetzke GD. The association between the fear of crime, and mental and physical wellbeing in New Zealand. Soc Indic Res. 2014;119(1):281-94.

20. Browning CR, Cagney KA, Iveniuk J. Neighborhood stressors and cardiovascular health: crime and C-reactive protein in Dallas, USA Soc Sci Med. 2012;75:1271-9.

21. Pearson AL, Bentham G, Day P, Kingham S. Associations between neighbourhood environmental characteristics and obesity and related behaviours among adult New Zealanders. BMC Public Health. 2014;14(1):553.

22. South EC, Hohl BC, Kondo MC, MacDonald JM, Branas CC. Effect of greening vacant land on mental health of community-dwelling adults. JAMA Netw Open. 2018;1(3):e180298.

23. Pearson AL, Sadler RC, Kruger DJ. Social integration may moderate the relationship between neighborhood vacancy and mental health outcomes: initial evidence from Flint, Michigan. Appl Res Qual Life. 2018;14(4):1129-44.

24. Groff E, McCord ES. The role of neighborhood parks as crime generators. Secur J. 2012;25(1):1-24.

25. Breetzke G, Pearson AL, Tao S, Zhang R. Greenspace and gun violence in Detroit, USA. Int J Crim Justice Sci. 2020;15(1):247-64.

26. Garvin EC, Cannuscio CC, Branas CC. Greening vacant lots to reduce violent crime: a randomised controlled trial. Inj Prev. 2013;19:198-203.

27. Zandieh R, Martinez J, Flacke J, Jones P, van Maarseveen M. Older adults' outdoor walking: inequalities in neighbourhood safety, pedestrian infrastructure and aesthetics. Int J Environ Res Public Health. 2016;13(12):1179

28. Berman MG, Kross E, Krpan KM Askren MK, Burson A, Deldin PJ, et al. Interacting with nature improves cognition and affect for individuals with depression. J Affect Disord. 2012;140(3):300-5.

29. Cox DTC, Shanahan DF, Hudson HL, Plummer KE, Siriwardena GM, Fuller RA, et al. Doses of neighborhood nature: the benefits for mental health of living with nature. Bioscience. 2017;67(2):147-55.

30. Tilt JH, Unfried TM, Roca B. Using objective and subjective measures of neighborhood greenness and accessible destinations for 
understanding walking trips and BMl in Seattle, Washington. Am J Health Promot. 2007;21 (4 Suppl):371-9.

31. Bell JF, Wilson JS, Liu GC. Neighborhood greenness and 2-year changes in body mass index of children and youth. Am J Prev Med. 2008;35(6):547-53.

32. Lovasi GS, Jacobson JS, Quinn JW, Neckerman KM, Ashby-Thompson $\mathrm{MN}$, Rundle A. Is the environment near home and school associated with physical activity and adiposity of urban preschool children? J Urban Health Bull N Y Acad Med. 2011:88(6):1143-57.

33. Lovasi GS, Bader MD, Quinn J, Neckerman K, Weiss C, Rundle A. Body mass index, safety hazards, and neighborhood attractiveness. Am J Prev Med. 2012;43(4):378-84.

34. Pereira G, Christian H, Foster S, Boruff B, Bull F, Knuiman M, et al. The association between neighborhood greenness and weight status: an observational study in Perth Western Australia. Environ Health. 2013;12(49):1-9.

35. Michimi A, Wimberly MC. Natural environments, obesity, and physical activity in nonmetropolitan areas of the United States. J Rural Health. 2012;28(4):398-407.

36. Wilson-Genderson M, Pruchno R. Effects of neighborhood violence and perceptions of neighborhood safety on depressive symptoms of older adults. Soc Sci Med. 2013;85:43-9.

37. Roman CG, Chalfin A. Fear of walking outdoors: a multilevel ecologic analysis of crime and disorder. Am J Prev Med. 2008:34(4):306-12.

38. Schweitzer JH, Kim JW, Mackin JR. The impact of the built environment on crime and fear of crime in urban neighborhoods. J Urban Technol. 1999:6:59-73.

39. Lapham SC, Cohen DA, Han B, Williamson S, Evenson KR, McKenzie $\mathrm{TL}$, et al. How important is perception of safety to park use? A fourcity survey. Urban Stud. 2016;53(12):2624-36.

40. Lorenc T, Clayton S, Neary D, Whitehead M, Petticrew M, Thomson $\mathrm{H}$, et al. Crime, fear of crime, environment, and mental health and wellbeing: mapping review of theories and causal pathways. Health Place. 2012;18:757-65.

41. Baldock KL, Paquet C, Howard NJ, Coffee NT, Taylor AW, Daniel M. Gender-specific associations between perceived and objective neighbourhood crime and metabolic syndrome. PLOS ONE. 2018;13(7):e0201336.

42. Silverman MN, Sternberg EM. Glucocorticoid regulation of inflammation and its functional correlates: from HPA axis to glucocorticoid receptor dysfunction. Ann N Y Acad Sci. 2012;1261:55-63.

43. Edwards C. Sixty years after Hench — corticosteroids and chronic inflammatory disease. J Clin Endocrinol Metab. 2012;97(5):1443-51.

44. Ligier S, Sternberg EM. Neuroendocrine host factors and inflammatory disease susceptibility. Environ Health Perspect. 1999;107(Suppl 5):701-7.

45. Sternberg EM. Neural regulation of innate immunity: a coordinated nonspecific host response to pathogens. Nat Rev Immunol. 2006:6(4):318-28.

46. Glaser R, Kiecolt-Glaser JK. Stress-induced immune dysfunction: implications for health. Nat Rev Immunol. 2005;5(3):243-51.

47. Godbout JP, Glaser R. Stress-induced immune dysregulation: implications for wound healing, infectious disease and cancer. J Neuroimmune Pharmacol. 2006;1 (4):421-7.

48. Slavich GM, Irwin MR. From stress to inflammation and major depressive disorder: a social signal transduction theory of depression. Psychol Bull. 2014:140(3):774-815

49. Ramos-Nino ME. The role of chronic inflammation in obesity-associated cancers. ISRN Oncol. 2013;2013:697521.

50. Sotos-Prieto M, Bhupathiraju SN, Falcon LM, Gao X, Tucker KL, Mattei J. A healthy lifestyle score is associated with cardiometabolic and neuroendocrine risk factors among puerto rican adults. J Nutr. 2015;145(7):1531-40.

51. Verratti V. Neuroimmune biology of physical exercise. J Biol Regul Homeost Agents. 2009;23(3):203-6.

52. Jacobsen HB, Reme SE, Sembajwe G, Hopcia K, Stiles TC, Sorensen G, et al. Work stress, sleep deficiency, and predicted 10-year cardiometabolic risk in a female patient care worker population. Am J Ind Med. 2014;57(8):940-9.
53. Palacios G, Pedrero-Chamizo R, Palacios N, Maroto-Sanchez B, Aznar S, Gonzalez-Gross M, et al. Biomarkers of physical activity and exercise. Nutr Hosp. 2015;31(Suppl 3):237-44.

54. Parente V, Hale L, Palermo T. Association between breast cancer and allostatic load by race: national health and nutrition examination survey 1999-2008. Psychooncology. 2013;22(3):621-8.

55. Acabchuk RL, Kamath J, Salamone JD, Johnson BT. Stress and chronic illness: the inflammatory pathway. Soc Sci Med. 2017;185:166-70.

56. Hu F, Li T, Colditz G, Willett W, Manson J. Television watching and other sedentary behaviors in relation to risk of obesity and type 2 diabetes mellitus in women. JAMA. 2003;289:1785-91.

57. Matsushita K, Blecker S, Pazin-Filho A, Bertoni A, Chang PP, Coresh J, et al. The association of hemoglobin a $1 \mathrm{c}$ with incident heart failure among people without diabetes: the atherosclerosis risk in communities study. Diabetes. 2010;59(8):2020-6

58. Selvin E, Steffes MW, Zhu H, Matsushita K, Wagenknecht L, Pankow J, et al. Glycated hemoglobin, diabetes, and cardiovascular risk in nondiabetic adults. N Engl J Med. 2010;362(9):800-11.

59. Schmidt HD, Shelton RC, Duman RS. Functional biomarkers of depression: diagnosis, treatment, and pathophysiology. Neuropsychopharmacology. 2011;36(12):2375-94.

60. International Diabetes Federation Guideline Development G. Global guideline for type 2 diabetes. Diabetes Res Clin Pract. 2014;104(1):1-52.

61. Thompson Coon J, Boddy K, Stein K, Whear R, Barton J, Depledge MH. Does participating in physical activity in outdoor natural environments have a greater effect on physical and mental wellbeing than physical activity indoors? A systematic review. Environ Sci Technol. 2011;45(5):1761-72.

62. MacLean PS, Wing RR, Davidson T, Epstein L, Goodpaster B, Hall KD, et al. $\mathrm{NIH}$ working group report: innovative research to improve maintenance of weight loss. Obesity. 2015;23(1):7-15.

63. Peters A, McEwen BS. Stress habituation, body shape and cardiovascular mortality. Neurosci Biobehav Rev. 2015;56:139-50.

64. Shortt NK, Rind E, Pearce J, Mitchell R, Curtis S. Alcohol risk environments, vulnerability, and social inequalities in alcohol consumption. Ann Am Assoc Geogr. 2018;108(5):1210-27.

65. Gascon M, Triguero-Mas M, Martinez D, Dadvand P, Forns J, Plasencia A, et al. Mental health benefits of long-term exposure to residential green and blue spaces: a systematic review. Int J Environ Res Public Health. 2015;12(4):4354-79.

66. Lenhart CM, Wiemken A, Hanlon A, Perkett M, Patterson F. Perceived neighborhood safety related to physical activity but not recreational screen-based sedentary behavior in adolescents. BMC Public Health. 2017;17(1):722.

67. Cohen S, Kamarck T, Mermelstein R. A global measure of perceived stress. J Health Soc Behav. 1983:24:385-96.

68. Solivan AE, Xiong X, Harville EW, Buekens P. Measurement of perceived stress among pregnant women: a comparison of two different instruments. Matern Child Health J. 2015;19(9):1910-5.

69. Khalili R, Sirati Nir M, Ebadi A, Tavallai A, Habibi M. Validity and reliability of the Cohen 10-item Perceived Stress Scale in patients with chronic headache: Persian version. Asian J Psychiatr. 2017;26:136-40.

70. Baik SH, Fox RS, Mills SD, Roesch SC, Sadler GR, Klonoff EA, et al. Reliability and validity of the Perceived Stress Scale-10 in Hispanic Americans with English or Spanish language preference. J Health Psychol. 2019;24(5):628-39.

71. Ader DN. Developing the patient-reported outcomes measurement information system (PROMIS). Med Care. 2007:45(5):S1-2.

72. Cella D, Yount S, Rothrock N, Gershon R, Cook K, Reeve B, et al. The patient-reported outcomes measurement information system (PROMIS): progress of an NIH Roadmap cooperative group during its first two years. Med Care. 2007:45(5 Suppl 1):S3-11.

73. Schalet BD, Pilkonis PA, Yu L, Dodds N, Johnston KL, Yount S, et al. Clinical validity of PROMIS depression, anxiety, and anger across diverse clinical samples. J Clin Epidemiol. 2016;73:119-27.

74. Tang E, Ekundayo O, Peipert JD, Edwards N, Bansal A, Richardson C, et al, Validation of the patient-reported outcomes measurement information system (PROMIS)-57 and -29 item short forms among kidney transplant recipients. Qual Life Res. 2019;28(3):815-27.

75. Clevenger KA, Pfeiffer KA, Montoye AHK. Cross-generational comparability of hip- and wrist-worn ActiGraph GT3X+, wGT3X-BT, 
and GT9X accelerometers during free-living in adults. J Sports Sci. 2020;38(24):2794-802.

76. Peeters G, van Gellecum Y, Ryde G, Farías NA, Brown WJ. Is the pain of activity log-books worth the gain in precision when distinguishing wear and non-wear time for tri-axial accelerometers? J Sci Med Sport. 2013;16(6):515-9.

77. Miqueles JH, Cadenas-Sanchez C, Ekelund U, Nyström CD, Mora-Gonzalez J, Löf M, et al. Accelerometer data collection and processing criteria to assess physical activity and other outcomes: a systematic review and practical considerations. Sports Med. 2017;47(9):1821-45.

78. Freedson P, Melanson E, Sirard J. Calibration of the computer science and applications, Inc. accelerometer. Med Sci Sports Exerc. 1998;30:777-81.

79. Szablowski CJ, Suscha E, Davis K, Xie CZ, Moskowitz K, Anderson JH, et al. Point-of-Care HbA1c-a case for diabetes screening and diagnosis. Diabetes. 2018;67(Supplement 1):1518.

80. Saelens BE, Sallis JF, Black JB, Chen D. Neighborhood-based differences in physical activity: an environment scale evaluation. Am J Public Health. 2003;93:1552-8.

81. Forsyth A, Oakes JM, Schmitz KH. Test-retest reliability of the Twin Cities walking survey. J Phys Act Health. 2009;6(1):119-31.

82. Schroeder P. Wilbur M. 2012 National survey of bicyclist and pedestrian attitudes and behavior: findings report. Washington, DC: National Highway Traffic Safety Administration; 2013. Contract No. DOT HS 811841 B.

83. Ramos H, Gosse M, Pritchard P, Radice M, Grant J, Shakotko P, et al. How Haligonians perceive neighborhood change. In: May 2016 NCRP research symposium presentation; 2016.

84. Prouse V, Grant J, Ramos H, Radice M. Assessing neighbourhood change: gentrification and suburban decline in a mid-sized city. School of Planning, Dalhousie University; 2015.

85. Data Driven Detroit (D3). Turning the corner. 2018. https://datadriven detroit.org/blog/2018/03/22/turning-the-corner/.

86. Motor City Mapping. Motor City Mapping Portal. 2014. https://motor citymapping.org/\#t=overview\&s=detroit\& $\mathrm{f}=$ all.

87. Kind A. University of Wisconsin School of Medicine and Public Health. Area Deprivation Index. 5/1/2018 ed. 2018

88. Troiano RP, Berrigan D, Dodd KW, Masse LC, Tilert T, McDowell M. Physical activity in the United States measured by accelerometer. Med Sci Sports Exerc. 2008;40(1):181-8.

89. Breetzke GD, Pearson AL. The fear factor: examining the spatial variability of recorded crime on the fear of crime. Appl Geogr. 2014;46:45-52.

90. Pearson AL, Breetzke G, Ivory V. The effect of neighborhood recorded crime on fear: does neighborhood social context matter? Am J Community Psychol. 2015;56(1-2):170-9.

91. Lovasi GS, Goh CE, Pearson AL, Breetzke G. The independent associations of recorded crime and perceived safety with physical health in a nationally representative cross-sectional survey of men and women in New Zealand. BMJ Open. 2014;4(3):e004058.

92. Morrall P, Marshall P, Pattison S, Macdonald G. Crime and health: a preliminary study into the effects of crime on the mental health of UK university students. J Psychiatry Ment Health Nurs. 2010;17(9):821-8.

93. White M, KasI SV, Zahner GEP, Will JC. Perceived crime in the neighborhood and mental health of women and children. Environ Dev. 1987;19:588-613.

94. Roberts B, Stickley A, Petticrew M, McKee M. The influence of concern about crime on levels of psychological distress in the former Soviet Union. J Epidemiol Community Health. 2012;66:433-9.

95. Ross CE. Fear of victimization and health. J Quant Criminol. 1993;9(2):159-75

96. Wang R, Yuan Y, Liu Y, Zhang J, Liu P, Lu Y, et al. Using street view data and machine learning to assess how perception of neighborhood safety influences urban residents' mental health. Health Place. 2019;59:102186.

97. Rees-Punia E, Hathaway ED, Gay JL. Crime, perceived safety, and physical activity: a meta-analysis. Prev Med. 2018;111:307-13.

98. Lachowycz K, Jones AP. Greenspace and obesity: a systematic review of the evidence. Obes Rev. 2011;12(5):e183-9.

99. Forsyth A, Wall M, Choo T, Larson N, Van Riper D, Neumark-Sztainer D. Perceived and police-reported neighborhood crime: linkages to adolescent activity behaviors and weight status. J Adolesc Health. 2015;57(2):222-8

100. Fish JS, Ettner S, Ang A, Brown AF. Association of perceived naighborhood safety on body mass index. Am J Public Health. 2010;100(11):2296-303.

101. Gary-Webb TL, Egnot NS, Nugroho A, Dubowitz T, Troxel WM. Changes in perceptions of neighborhood environment and cardiometabolic outcomes in two predominantly African American neighborhoods. BMC Public Health. 2020;20(1):52.

102. Sampson N, Nassauer J, Schulz A, Hurd K, Dorman C, Ligon K. Landscape care of urban vacant properties and implications for health and safety: lessons from photovoice. Health Place. 2017;46:219-28.

103. Olafsdottir G, Cloke P, Vogele C. Place, green exercise and stress: an exploration of lived experience and restorative effects. Health Place. 2017:46:358-65.

104. Pretty J, Peacock J, Sellens M, Griffin M. The mental and physical health outcomes of green exercise. Int J Environ Health Res. 2005;15:319-37.

105. Shanahan DF, Bush R, Gaston KJ, Lin BB, Dean J, Barber E, et al. Health benefits from nature experiences depend on dose. Sci Rep. 2016;6:28551.

106. Garvin EC, Cannuscio CC, Branas CC. Greening vacant lots to reduce violent crime: a randomised controlled trial. Inj Prev. 2013;19(3):198-203.

107. Branas CC, Cheney RA, MacDonald JM, Tam VW, Jackson TD, Ten Have TR. A difference-in-differences analysis of health, safety, and greening vacant urban space. Am J Epidemiol. 2011;174:1296-306.

108. South EC, Kondo MC, Cheney RA, Branas CC. Neighborhood blight, stress, and health: a walking trial of urban greening and ambulatory heart rate. Am J Public Health. 2015;105:909-13.

109. Page-Reeves J, Niforatos J, Mishra S, Regino L, Gingrich A, Bulten R. Health disparity and structural violence: how fear undermines health among immigrants at risk for diabetes. J Health Dispar Res Pract. 2013;6(2):30-47.

110. Kamel Boulos MN, Yang SP. Mobile physical activity planning and tracking: a brief overview of current options and desiderata for future solutions. mHealth. 2020. https://doi.org/10.21037/mhealth.2020.01.01.

111. Christine PJ, Auchincloss AH, Bertoni AG, Carnethon MR, Sanchez BN, Moore K, et al. Longitudinal associations between neighborhood physical and social environments and incident type 2 diabetes mellitus: the multi-ethnic study of atherosclerosis (MESA). JAMA Intern Med. 2015;175(8):1311-20.

112. Smalls BL, Gregory CM, Zoller JS, Egede LE. Assessing the relationship between neighborhood factors and diabetes related health outcomes and self-care behaviors. BMC Health Serv Res. 2015:15:445.

113. Manson S, Schroeder J, Van Riper D, Kugler T, Ruggles S. IPUMS National Historical Geographic Information System: version 15.0. Minneapolis: IPUMS; 2020. https://doi.org/10.18128/D050.V15.0.

\section{Publisher's Note}

Springer Nature remains neutral with regard to jurisdictional claims in published maps and institutional affiliations. 